\title{
PMB quality problems based on its morphology and used equipment
}

\author{
Marina Vysotskaya ${ }^{1, *}$, Evgeniy Kharlamov ${ }^{2}$, Vasily Denisov ${ }^{1}$, and Anastasiya Kurlykina ${ }^{1}$ \\ ${ }^{1}$ Belgorod State Technological University VG Shukhov, Kostukova str., 46, Belgorod, 308012, \\ Russia \\ ${ }^{2}$ Moscow State University of Civil Engineering, Yaroslavl h., 26, Moscow, 129337, Russia
}

\begin{abstract}
In the first part of the study, a direct relationship is established between the influence of the morphology of PMB (polymer modified binder) on the totality of its consumer properties and its tendency to destruction. The second part of the study is devoted to the influence of technological equipment used for the production of polymer modified binder on its properties. It was experimentally established that having the same initial components, PMB of completely different quality were obtained at the output. According to the degree of increase in rigidity (penetration value at $25{ }^{\circ} \mathrm{C}$ ), obtained PMBs can be conditionally positioned as follows: prepared using a paddle mixer, a colloid mill, and an extruder. It is proved that the high elastic properties of PMB can be achieved by using paddle mixers that do not damage the long polymer macromolecules during the process. However, such binders are prone to delamination. To eliminate this negative aspect, the use of additional crosslinking agents is necessary. PMB prepared using an extruder has lost its elastic abilities, has become tough, with a high rate of cohesive strength. Thus, it is noted that when designing PMB compositions, it is necessary to carefully choose not only the raw material base but also the technological equipment for its preparation.
\end{abstract}

\section{Introduction}

There are many examples in the world around us, when representatives of different species of animals, plants, substances live, contact and are forced to interact with each other for various reasons. Such relationships are called symbiosis. However, symbiosis is a tricky thing and takes on completely unexpected forms. Mutualism is one form of symbiosis when partnership brings mutual benefits. If in contact one of the partners wins, and the other does not experience any harm or benefit from communication, then this is commensalism. And the critical form of interaction, often fatal, is parasitism, when one exists at the expense of the other.

Similar associations arose at the time when our group of colleagues, having completed the studies of polymer modified binders (PMB) manufactured by various manufacturers, were perplexedly considering microphotographs of films of the studied binders.

\footnotetext{
*Corresponding author: roruri@ rambler.ru
} 
The starting point of the study was article [1], the beginning of which was: “... but all PMB producers have almost one bitumen market, in which the majority of bitumen is produced according to a single standard, and one polymer market. Nevertheless, each of the manufacturers promises to supply the best, most effective and high-quality PMB...". Such a statement is fully true, but it turns out in practice that the binder supplied to the consumer has completely different quality indicators. The question why this is happening has been rhetorical and debatable for a long time [2-6].

Of course, a technological arrangement of the process of its preparation makes a significant contribution to the quality of a marketable product. Nowadays, the following technological equipment is used to prepare PMB: a colloidal mill, an extruder, a mechanical mixer, and a hydrodynamic cavitation mixer [7]. The latter, however, did not take hold.

Each method is based on technological features peculiar only to it [8-10]. "EMOTE-4" Benninghoven plant (Germany) is a container type with automatic control and electric heating with a capacity of 5-6 t/h. The equipment includes a Tekno high-frequency colloidal mill. Mixer for mixing bitumen by "GK PromEcoVector" LLC is a blade type electric mixer with a capacity of $3 \mathrm{~kW}$, the mixed volume is $5.0-6.3 \mathrm{~m}^{3}$. In the extruder ("Davial Mechanic" LLC), the extrusion of the polymer occurs, which combine the mixing and dissolution of the resulting melt with a certain amount of bitumen or plasticizer. Productivity up to $10 \mathrm{t} / \mathrm{h}$. For example, a colloidal mill is a high-speed homogenizer in which the mixing of the components and the grinding of the polymer occur as a result of shear deformation that occurs in the gaps between the stator and the rotor. In a number of models, it is possible to control the degree of polymer grinding and the plant productivity by varying the gap size and rotor speed.

The extruder in PMB manufacturing technology is a worm gear in which the worm rotates and reciprocates simultaneously. To intensify the process, teeth are installed on the inner surface of the case, which enter the grooves located in a certain order between the turns of the worm. This determines the movement of the material along a helical path alternately in axial and radial flow. In small volumes between the turns of the worm, the material is subjected to shear, compression, tension in various planes, leading to mixing. Extruder designs are diverse. The next equipment to be mentioned is a mechanical mixer. Here mixing occurs in laminar mode. When mixing, the mass of bitumen and polymer moves parallel to the path circumscribed by the working mixing body. It is possible to control the shaft rotation speed, the number of blades and the geometric parameters of the frames, which allows varying the performance of the plant and the quality of PMB.

As you can see, the process of mixing and homogenization of the components in each case occurs according to its own laws. Obviously, the output parameters of the PMB properties will be influenced not only by what it is made of, but also by what technological alterations it underwent during the production process.

Thus, the symbiosis of bitumen, polymer and, if necessary, additional components, which currently has a high-profile name: " 4 th generation bitumen products - polymer modified binders capable of simultaneously providing the necessary temperature crack resistance, high corrosion resistance, heat resistance, shear resistance, and the long-term durability of pavements [1]" is quite controversial. This is evidenced by an extensive selection on the preparation, use of PMB, as well as the destructive processes to which it is subject $[4,11,12]$.

The amount of information and opinions, the abundance of advertising products and disparate "unfamiliar" experimental data on the influence of various factors on the consumer properties of PMB prompted keen curiosity and a desire to study and compare the models of modified binder available on the market. And also to carry out comparative studies on the impact of the used technological equipment for the preparation of PMB. 


\section{Materials and Methods}

The objects of the study in the paper were PMB-60 samples from various manufacturers. Conventionally, the study can be divided into two stages. The purpose of the first part of the experiment was to study the quality of commercial PMB coming from the manufacturer to the factory of the consumer and get an answer whether all the binders are the same or are there any tricks to modify bitumen. At the same time, it was assumed that all binders are made from high-quality (corresponding to Russian State Standard) raw materials using modern equipment and effective technologies, which were not possible to trace (in accordance with the manufacturer's advertising).

PMB-60 samples of seven manufacturers were tested. When setting up the experiment, standard parameters of the properties of modified bitumen and the cohesive adhesion strength of organic binders were studied using a Controls 80-B0193 device in accordance with EN 12274-4.

PMB cohesion was determined using a Controls 80-B193 device at a pressure of 200 $\mathrm{kPa}$ for $5 \mathrm{~s}$. The essence of the method is to prepare binder samples by pouring it into brass rings with a diameter of $60 \mathrm{~mm}$ at a temperature of $160{ }^{\circ} \mathrm{C}$, located in the center of the squares of the roofing material. Torque measurements were carried out in 24 hours after pouring. The test sample was located in the center under the neoprene base, the air pressure of the device was set equal to $200 \mathrm{kPa}$, the piston fell to the sample at a speed of $10 \mathrm{~cm} / \mathrm{sec}$. After 5 seconds of compaction, the moment meter was zeroed, placed on the upper edge of the cylinder rod and twisted in a smooth, constant, horizontal movement at an angle from $90^{\circ}$ to $120^{\circ}$ for 5 seconds. The achieved torque and time were fixed.

The tendency of the binder to degradation was also assessed, which was judged by the stability of the modified bitumen during storage according to the method of Russian State Standard GOST EN 13399-2013 (delamination in a tube) after heating for 72 hours at a temperature of $163{ }^{\circ} \mathrm{C}$, a change in the softening temperature after heating at a temperature of $163{ }^{\circ} \mathrm{C}$ for 5 hours, as well as resistance to aging according to the TFOT method.

For the binder samples subjected to a delamination test, the difference in softening and fragility temperatures at the top and bottom of the tube was determined. The stability of PMB was studied by the value of the difference in indicators.

During the aging test according to the TFOT method, the following changes were assessed: changes in mass, softening temperature, and also the cohesive strength of the modified binder.

The morphology of the tested samples was studied using scanning electron microscopy (SEM) using a TESCAN MIRA 3 LMU high resolution scanning electron microscope. To be able to compare visual data, binder samples with the same mass were applied to special substrates with a fixed surface area. After that, the study of the morphology of the modified binder was performed for no more than 3 minutes. Further, the sample was melted and lost continuity.

At the second stage of the experiment, the impact of technological equipment on the performance indicators of PMB-60 was assessed. Samples of binder produced using the BENNINGHOVEN plant with a capacity of $30 \mathrm{t} / \mathrm{h}$, using an extruder with a capacity of 10 $\mathrm{t} / \mathrm{h}$, and using a mechanical mixer of GK PromEcoVector LLC were subjected to comparative analysis. A table with the technical characteristics of the equipment is presented in table 1.

The raw materials were identical: bitumen BND 70/100 - 95.4\%, SBS polymer - 3.4\%, plasticizer extract of the A class - 1.2\%. Bitumen indicators are presented in table 1 . 
Table 1. Physico-mechanical properties of bitumen BND 70/100

\begin{tabular}{|c|c|c|}
\hline \multirow[t]{2}{*}{ Name of indicators } & $\begin{array}{c}\text { Requirements of the } \\
\text { Russian State Standard } \\
\text { GOST } 33133 \\
\end{array}$ & Actual results \\
\hline & \multicolumn{2}{|c|}{$70 / 100$} \\
\hline $\begin{array}{l}\text { Needle penetration depth }(0.1 \mathrm{~mm}) \text {, } \\
\text { at } 25^{\circ} \mathrm{C} \\
\text { at } 0^{\circ} \mathrm{C}\end{array}$ & $\begin{array}{c}71-100 \\
>21\end{array}$ & $\begin{array}{l}77 \\
24\end{array}$ \\
\hline $\begin{array}{l}\text { Elasticity, cm, } \\
\text { at } 25^{\circ} \mathrm{C} \\
\text { at } 0^{\circ} \mathrm{C}\end{array}$ & $\begin{array}{l}>62 \\
>3.7\end{array}$ & $\begin{array}{l}100 \\
3.7\end{array}$ \\
\hline $\begin{array}{l}\text { Maximum tensile force, } \mathrm{N} \text {, at temperature, } \\
\text { at } 25^{\circ} \mathrm{C} \\
\text { at } 0^{\circ} \mathrm{C}\end{array}$ & $\begin{array}{l}- \\
-\end{array}$ & $\begin{array}{l}1.2 \\
118\end{array}$ \\
\hline Softening temperature ${ }^{0} \mathrm{C}$, & $>47$ & 49.5 \\
\hline Brittle temperature, ${ }^{\circ} \mathrm{C}$ & $<-18$ & -22 \\
\hline Dynamic viscosity, Pa $\bullet$ s, at $60^{\circ} \mathrm{C}$, Condition 1 & - & 245.5 \\
\hline $\begin{array}{l}\text { Change in dynamic viscosity after shear, Pa } \bullet \text {, at } \\
60^{\circ} \mathrm{C} \text {, Condition } 2\end{array}$ & - & 12.97 \\
\hline \multicolumn{3}{|l|}{ RTFOT post-aging tests } \\
\hline Change in mass of the sample after aging, $\%$ & $<0.6$ & 0.2 \\
\hline Change in softening temperature, ${ }^{\circ} \mathrm{C}$, after aging & $<7$ & 6.2 \\
\hline $\begin{array}{l}\text { Dynamic viscosity after aging, Pa•s, at } 60^{\circ} \mathrm{C}, \\
\text { Condition } 1\end{array}$ & - & 667.11 \\
\hline $\begin{array}{l}\text { Change in dynamic viscosity after shear, after } \\
\text { aging, Pa } \bullet \text { s, at } 60^{\circ} \mathrm{C} \text {, Condition } 2\end{array}$ & - & 24.72 \\
\hline
\end{tabular}

The PMB-60 preparation technology consisted of 2 stages: mixing the components and ripening of the modified binder. The resulting binder was evaluated according to standard quality indicators. The reliability of the obtained data was ensured by an increased sampling of parallel series of test samples (at least 5).

\section{$3 \quad$ Main part}

\subsection{The influence of PMB morphology on its physical and mechanical properties}

The most important factor in the preparation of quality and durability of both PMB and asphalt concrete in the coating of roads based on it is the compatibility of bitumen with the polymer used. This is especially important since, in contrast to bitumen, PMB, along with the coagulation framework of asphaltene complexes, must contain an additional elastic structural network of macromolecules of the block-copolymer of the SBS type, which determines the difference between its properties and those of bitumen on the one hand. Moreover, the minimum polymer content according to [12], at which this mesh is formed, is $2-2.5 \%$ of the polymer by weight. The increase in polymer content increases the strength of the mesh, and, consequently, the elasticity, heat resistance of PMB and crack resistance due to the orientation effect.

On the other hand, when the components are combined, the polymer acts as a competitor to asphaltene complexes in the "struggle" for the maltene component of bitumen, which is necessary for the polymer units to swell before homogenizing the combined system. The higher the polymer content, the sharper the competition that causes uneven stresses in the structure of the binder. 
Thus, in order for the polymer modified binder to have the right to be called PMB, not only any tiny granules of undissolved polymer should be absent and a mesh of homogenized polymer should be formed in the bitumen phase, but also a sufficient amount of maltene medium containing competing phases of asphaltenes and polymer macromolecules should be there. In other words, a symbiosis should be observed, as a result of which bitumen acts as a complex and multicomponent solvent for the polymer, the polymer dissolves to form a mesh, and together they complement each other and work as an effective composite. At the same time, the task of PMB developers and manufacturers is to obtain a durable and colloidal stability binder not only by varying the composition, but also by competent technological design of the process of preparing a modified binder.

Thus, we come to where the paper began. Symbiosis "bitumen-polymer" - mutualism or parasitism?

Based on the above conclusions, the study of the PMB series accepted for the study was started under a microscope, Fig. 1-7.
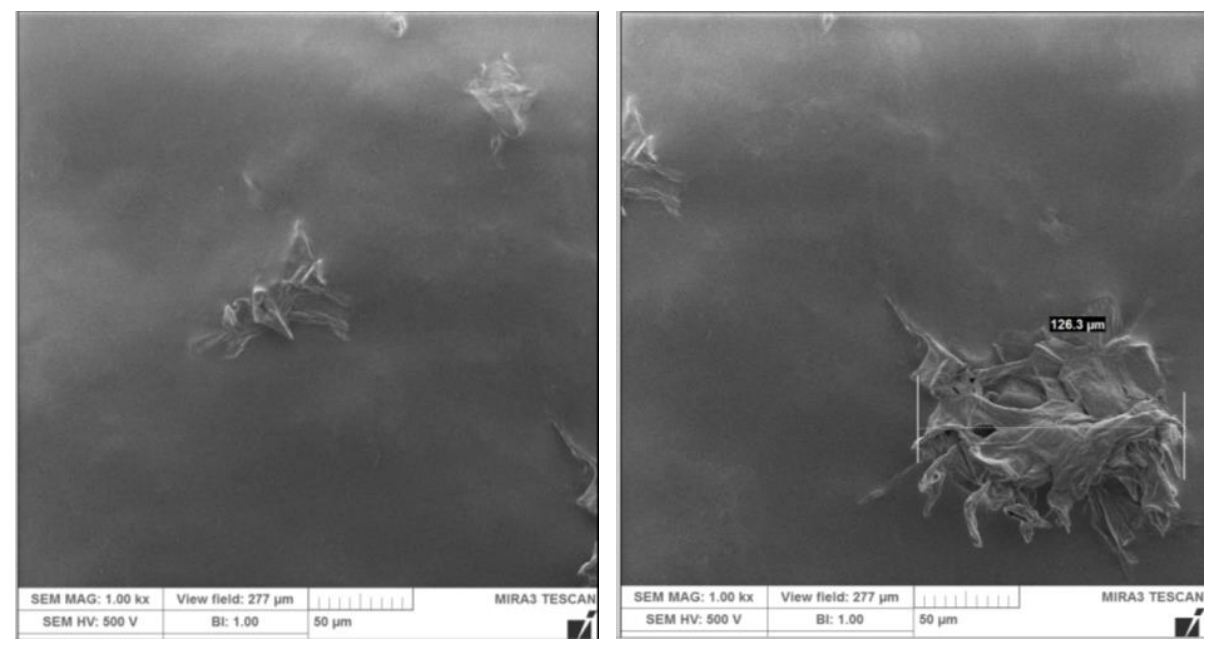

Fig.1. Micrographs of the morphology of the studied PMB sample 1 ( $a-$ left picture, $b$ - right picture)
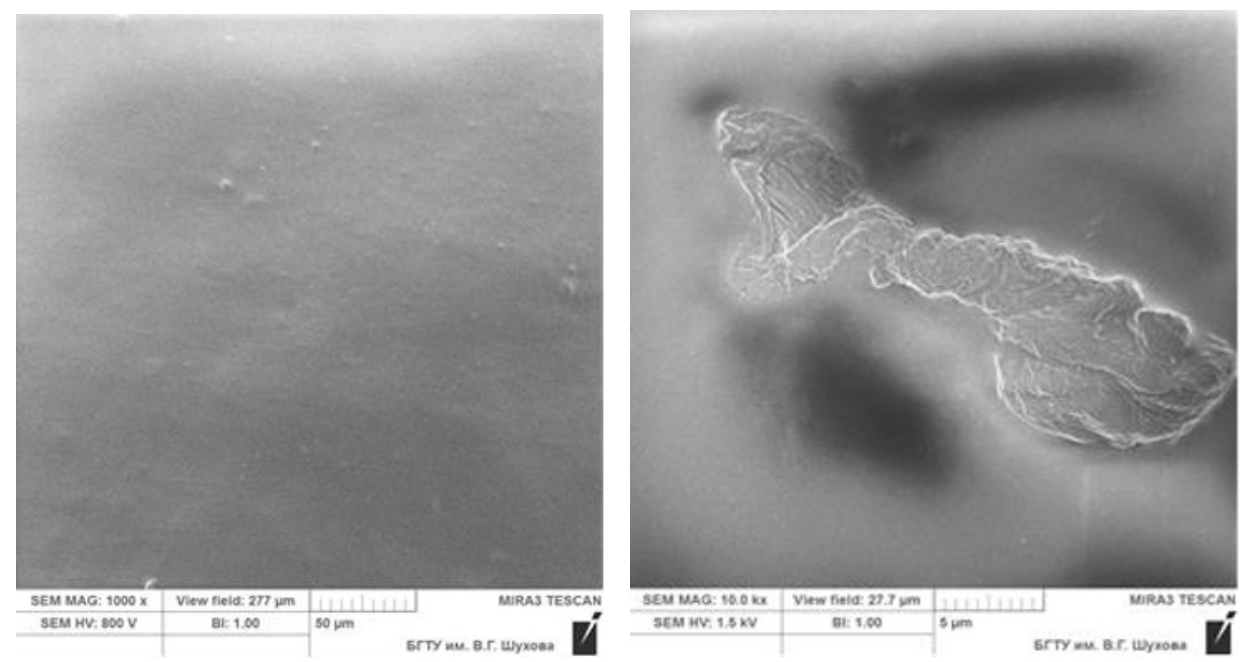

Fig. 2. Micrographs of the morphology of the studied PMB sample 2 (a - left picture, $b$ - right picture) 

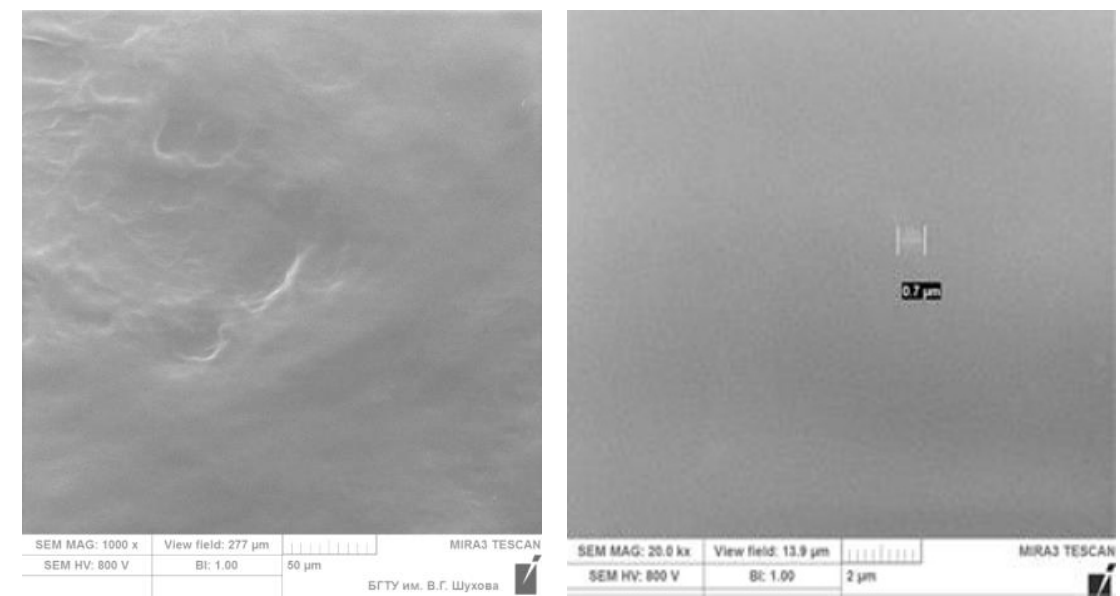

Fig. 3. Micrographs of the morphology of the studied PMB sample 3 (a - left picture, $b$ - right picture)
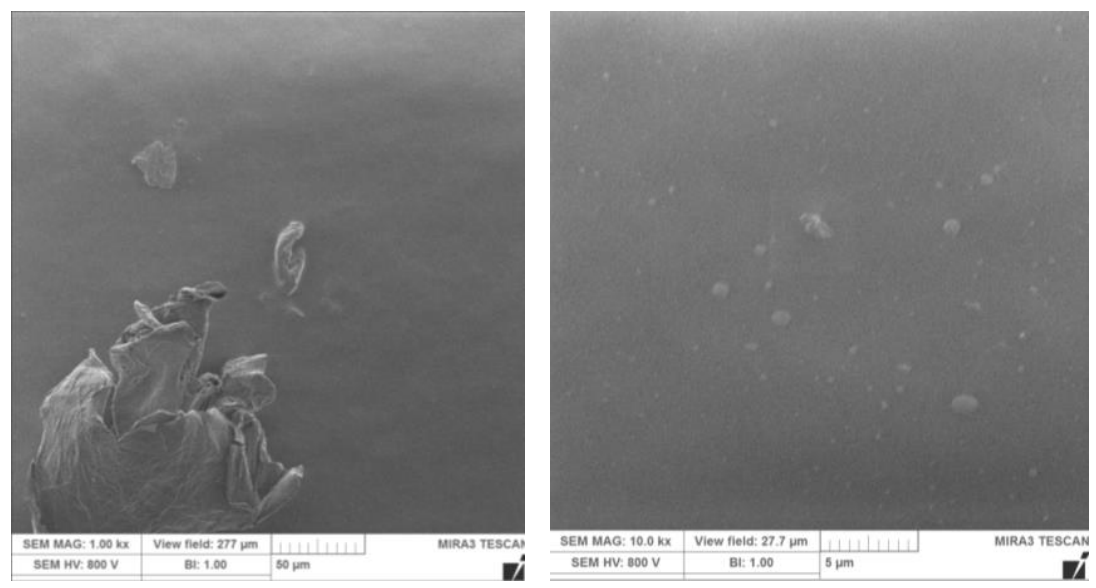

Fig. 4. Micrographs of the morphology of the studied PMB sample 4 (a - left picture, $b-$ right picture)
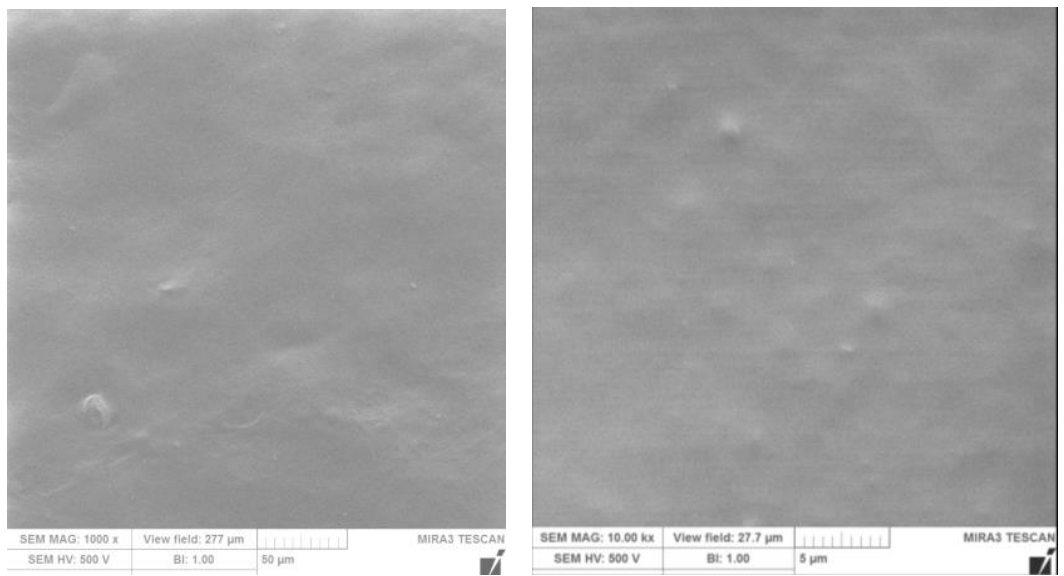

Fig. 5. Micrographs of the morphology of the studied PMB sample 5 ( $a$ - left picture, $b-$ right picture) 

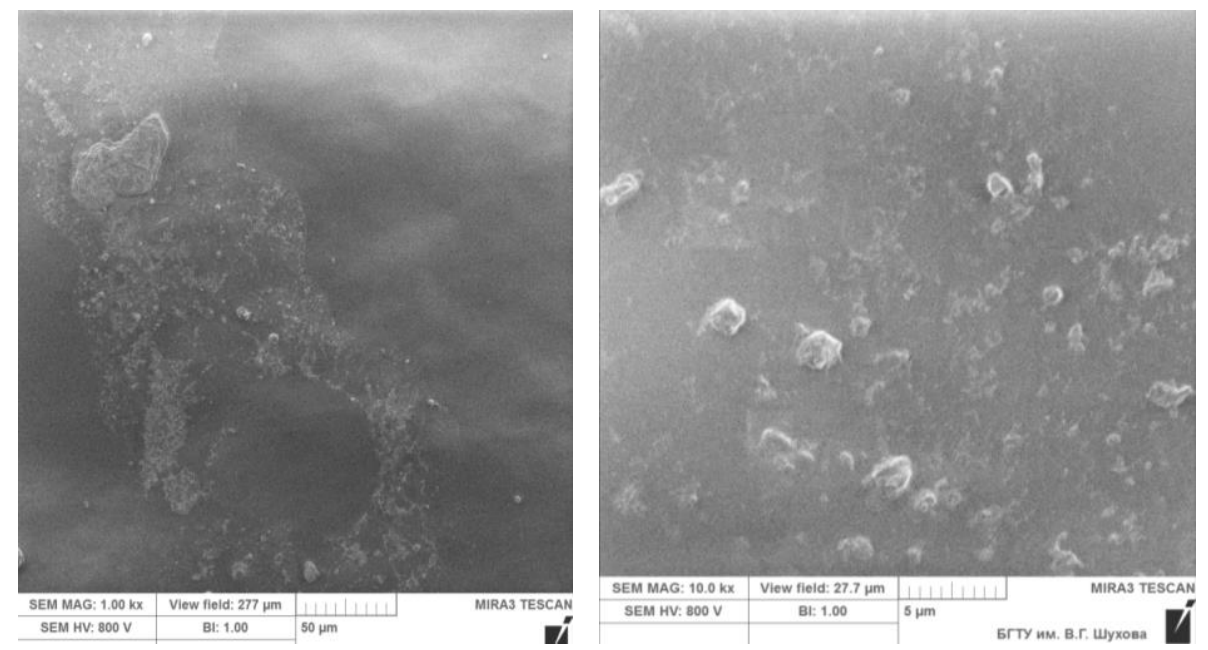

Fig. 6. Micrographs of the morphology of the studied PMB sample 6 (a - left picture, $b$ - right picture)
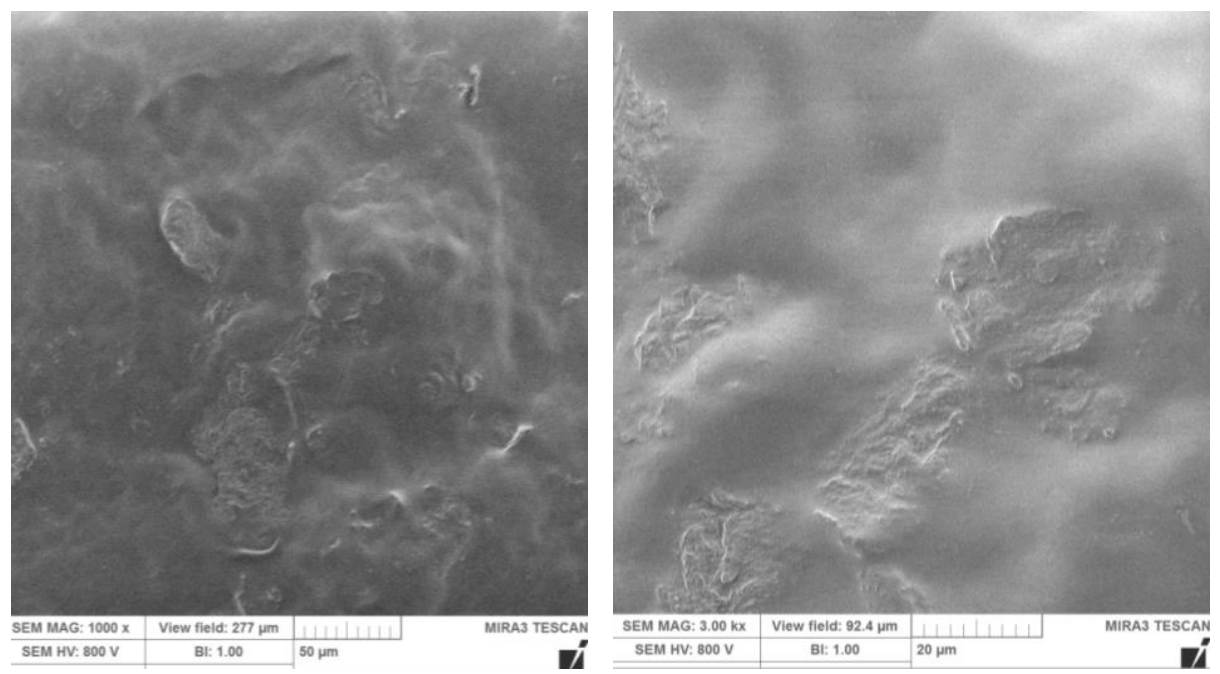

Fig. 7. Micrographs of the morphology of the studied PMB sample 7(a - left picture, $b$ - right picture)

The figures show that not all samples of the binders under consideration can be called homogeneous. Obviously, the data in Fig. 1, 4, 6, and 7 of a series of samples No. 1, No. 4, No. 6, and No. 7 cannot be attributed to mutualism. This is more like parasitism, when an insoluble polymer, pulling the maltene fraction out of bitumen, gives nothing in return. It can be assumed that these compositions will be characterized by destructive processes.

The homogeneous morphology of the polymer modified binder with a minimal inclusion of undissolved polymer particles was recorded in samples No. 2, No. 3, No. 5 (Fig. 2, 3, 5).

It is generally accepted $[13,14,15]$ that for PMB the presence of a polymer mesh in the structure is a desirable condition, and, according to some researchers, a necessary condition. It should be noted that during the study, this mesh was recorded only in sample No. 5, see Fig. 8. 


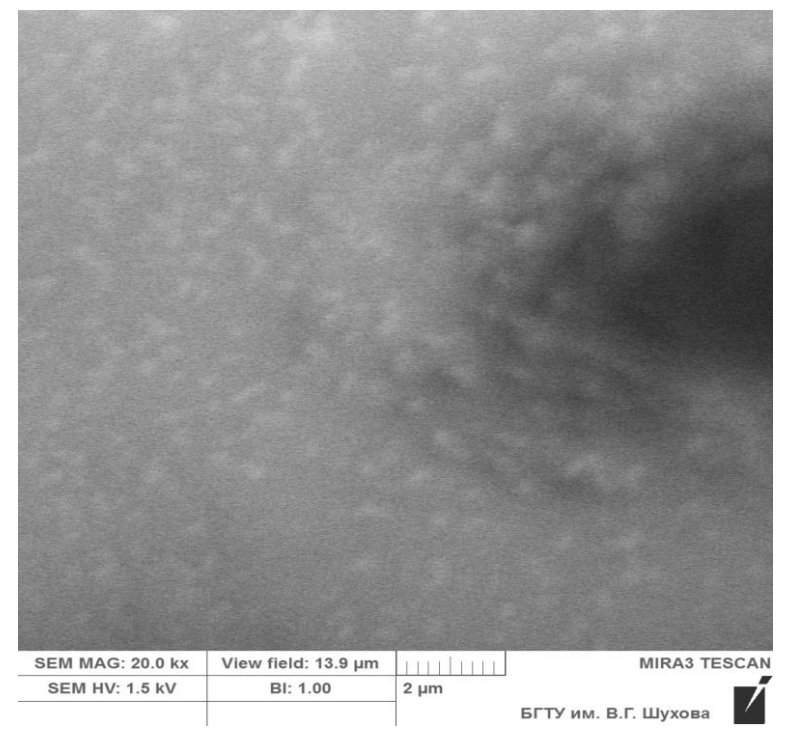

Fig. 8. Micrograph of the polymer mesh in PMB sample No. 5

The dark spot in the figure is the beginning of the temperature deformation of the PMB film. During the time required to increase the object to the presented dimensions and to focus the device on a sample containing volatile organic compounds, under the action of the electron probe, a charge accumulates on the surface of the sample, as a result of which it heats up and deforms. An increase in the observation time of PMB samples under a microscope for more than 3 min leads to burning of samples.

Of course, preparing PMB is a complex process. The intensity of dissolution and homogenization of the bitumen-polymer system is influenced by a number of factors, including the quality and nature of the initial bitumen, plasticizer (when added), the structure and molecular weight of the polymer macromolecules, its dispersion, and the technology of preparation of the binder. However, without fulfilling or neglecting one of these conditions, is it possible to obtain a quality product?

Organic binders are a rheologically complex form of liquids. There is a specific set of requirements for them. So, for example, when they are used in the composition of asphalt concrete pavement of roads, the binder sticking together the grains of mineral material must be in a solid consistency. However, for effective work with a binder, it is necessary that a certain viscosity correspond to each technological redistribution on the way of preparation of asphalt concrete mixtures. During the preparation of the binder for pumping through the system of pipelines at the asphalt concrete mixing plant, mixing with mineral materials into mixers, and laying the finished asphalt mixture, PMB should be liquid. To assess the contribution of the morphology of binders to the quality indicators of PMB-60, studies of their physical and mechanical properties were performed. The results are presented in tables 2 and 3.

When studying the standard properties of both bitumen and PMB, it must be understood that the binder as a raw material component of the asphalt mix and the binder in the composition of asphalt laid in the road surface can vary enormously. As part of even just the prepared mixture, bitumen undergoes technological aging. Thus, the assessment of the dynamics of changes in the properties of organic binders in the aging process at all technological stages is an urgent and necessary operation. 
Table 2. Properties of PMB-60 from various manufacturers

\begin{tabular}{|c|c|c|c|c|c|c|c|c|c|c|}
\hline \multirow{2}{*}{\multicolumn{3}{|c|}{ Name of indicator }} & \multirow{2}{*}{$\begin{array}{l}\text { Requirements } \\
\text { for PBV-60 } \\
\text { GOST, EN }\end{array}$} & \multicolumn{7}{|c|}{ No. of series of PMB -60 samples } \\
\hline & & & & No.1 & No. 2 & No.3 & No.4 & No.5 & No.6 & No.7 \\
\hline \multirow{6}{*}{ 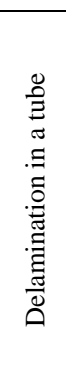 } & \multicolumn{2}{|c|}{ brittle temperature, ${ }^{0} \mathrm{C}$} & \multirow{3}{*}{-} & . & & & & & & \\
\hline & \multicolumn{2}{|c|}{ - tube top } & & -28 & -26 & -26 & -25 & -24 & -23 & - \\
\hline & \multicolumn{2}{|c|}{ - tube bottom } & & -20 & -26 & -22 & -22 & -22 & -21 & - \\
\hline & \multicolumn{2}{|c|}{$\begin{array}{l}\text { softening temperature, } \\
{ }^{0} \mathrm{C}\end{array}$} & \multirow{3}{*}{5} & & & & & & & \\
\hline & \multicolumn{2}{|c|}{ - tube top } & & 75 & 66 & 75 & 75 & 71 & 68 & - \\
\hline & \multicolumn{2}{|c|}{ - tube bottom } & & 63 & 66 & 75 & 68 & 69 & 66 & - \\
\hline \multicolumn{3}{|c|}{ Brittle temperature, ${ }^{\circ} \mathrm{C}$} & -20 & -20 & -24 & -24 & -22 & -23 & -21 & -19 \\
\hline \multicolumn{3}{|c|}{ Softening temperature, ${ }^{\circ} \mathrm{C}$} & 54 & 56 & 68 & 72 & 71 & 70 & 65 & 66 \\
\hline \multicolumn{3}{|c|}{ Homogeneity } & homogeneous & $\begin{array}{l}\text { not } \\
\text { hom. }\end{array}$ & hom. & hom. & hom. & hom. & hom. & $\begin{array}{l}\text { not } \\
\text { hom. }\end{array}$ \\
\hline \multicolumn{3}{|c|}{$\begin{array}{l}\text { Needle penetration depth }(0.1 \\
\mathrm{mm}) \text {, } \\
\text { at } 25^{\circ} \mathrm{C} \\
\text { at } 0^{\circ} \mathrm{C}\end{array}$} & $\begin{array}{l}60 \\
32\end{array}$ & $\begin{array}{l}66 \\
36\end{array}$ & $\begin{array}{l}63 \\
32\end{array}$ & $\begin{array}{l}78 \\
33\end{array}$ & $\begin{array}{l}65 \\
41\end{array}$ & $\begin{array}{l}63 \\
36\end{array}$ & $\begin{array}{l}67 \\
38\end{array}$ & $\begin{array}{l}60 \\
31\end{array}$ \\
\hline \multicolumn{3}{|c|}{$\begin{array}{l}\text { Extensibility, } \mathrm{cm}^{\Delta} \mathrm{L}, \\
\text { at } 25^{\circ} \mathrm{C} \\
\text { at } 0^{\circ} \mathrm{C}\end{array}$} & $\begin{array}{l}25 \\
11\end{array}$ & $\begin{array}{l}75 \\
12\end{array}$ & $\begin{array}{l}67 \\
30\end{array}$ & $\begin{array}{l}50 \\
33\end{array}$ & $\begin{array}{l}76 \\
21\end{array}$ & $\begin{array}{l}62 \\
45\end{array}$ & $\begin{array}{l}88 \\
28\end{array}$ & $\begin{array}{l}66 \\
10\end{array}$ \\
\hline \multicolumn{3}{|c|}{$\begin{array}{l}\text { Elasticity, } \% \Delta_{\mathrm{L}} \\
\text { at } 25^{\circ} \mathrm{C} \\
\text { at } 0^{\circ} \mathrm{C}\end{array}$} & $\begin{array}{l}80 \\
70\end{array}$ & $\begin{array}{l}92 \\
43\end{array}$ & $\begin{array}{l}93 \\
71\end{array}$ & $\begin{array}{l}85 \\
73\end{array}$ & $\begin{array}{l}95 \\
74\end{array}$ & $\begin{array}{l}96 \\
78\end{array}$ & $\begin{array}{l}98 \\
88\end{array}$ & $\begin{array}{l}88 \\
41\end{array}$ \\
\hline \multicolumn{3}{|c|}{$\begin{array}{l}\text { Resistance to delamination: } \\
-\quad \text { difference in brittle } \\
\text { temperature, }{ }^{0} \mathrm{C} \text { in softening } \\
-\quad \text { difference in sofence } \\
\text { temperature, }{ }^{0} \mathrm{C}\end{array}$} & $\overline{5}$ & $\begin{array}{l}8 \\
12\end{array}$ & $\begin{array}{l}0 \\
0\end{array}$ & $\begin{array}{l}4 \\
0\end{array}$ & $\begin{array}{l}3 \\
7\end{array}$ & $\begin{array}{l}2 \\
2\end{array}$ & $\begin{array}{l}2 \\
2\end{array}$ & $\begin{array}{l}- \\
-\end{array}$ \\
\hline \multicolumn{3}{|c|}{$\begin{array}{l}\text { Change in softening } \\
\text { temperature after warming up, } \\
{ }^{0} \mathrm{C}\end{array}$} & 5 & 9 & 3 & 2 & 6 & 3 & 5 & 7 \\
\hline \multirow{2}{*}{\multicolumn{2}{|c|}{$\begin{array}{l}\text { Resistance to } \\
\text { aging. } \\
\text { method }\end{array}$}} & $\begin{array}{l}\text { change in } \\
\text { weight, } \%\end{array}$ & - & 1.5 & 0.4 & 0.4 & 0.3 & 0.4 & 0.5 & 0.7 \\
\hline & & $\begin{array}{l}\text { change in } \\
\text { softening } \\
\text { temperature } \\
{ }^{0} \mathrm{C}\end{array}$ & - & 11 & 4 & 3 & 3 & 4 & 5 & 5 \\
\hline
\end{tabular}

Based on the analysis of table 2, it was found that the binder from series No. 7 does not correspond to the declared marking, is prone to aging and violation of sample continuity with little effort. According to formal signs: penetration, softening and brittle temperatures, extensibility, the rest of the studied binders correspond to PMB-60. However, the binder of series No. 1 is completely not homogeneous, prone to strong delamination and aging. The obtained data fully confirmed assumptions about the low quality of the binder, which were previously put forward and based on the analysis of photographs, Fig. 1, a. The cohesive strength of this sample is minimal. Moreover, after aging according to the TFOT method, Fig. 9, a drop in this indicator is observed, which corresponds to data on its aging. 
Obviously, the lack of homogeneity of the composition causes intense destructive processes in PMB.

Table 3. Change in the dynamic viscosity of the PMB-60 samples under the study

\begin{tabular}{|c|c|c|c|c|}
\hline $\begin{array}{c}\text { No. of series of } \\
\text { PMB-60 } \\
\text { samples }\end{array}$ & \multicolumn{2}{|c|}{ Dynamic viscosity, Pa॰s before aging } & \multicolumn{2}{c|}{ Dynamic viscosity, Pa॰s after aging } \\
\cline { 2 - 5 } & $135^{\circ} \mathrm{C}$ & $165^{\circ} \mathrm{C}$ & $135^{\circ} \mathrm{C}$ & $165^{\circ} \mathrm{C}$ \\
\hline 1 & 1.308 & 0.292 & \multicolumn{2}{|c|}{ significant variation in indicators } \\
\hline 2 & 1.866 & 0.423 & 2.241 & 0.507 \\
\hline 3 & 1.905 & 0.437 & 2.248 & 0.502 \\
\hline 4 & 1.448 & 0.307 & 1.448 & 0.307 \\
\hline 5 & 1.954 & 0.545 & 2.228 & 0.620 \\
\hline 6 & 1.508 & 0.362 & 1.267 & 0.301 \\
\hline 7 & 1.351 & 0.289 & significant variation in indicators \\
\hline
\end{tabular}

The purpose of the binder in the coating is to fasten the mineral core and for a long time to keep it in integral condition under the influence of intense and aggressive influences of various kinds. Therefore, the deformation indices of binders, which depend on their viscoelastic properties, on intrinsic strength and adhesion to a foreign surface, i.e. on their adhesion and cohesion, should be given increased attention. These characteristics are determined by the structure and chemical composition of PMB, and form their ability to withstand the aggressive effects of the environment for a long time and ensure the durability of the structures. Cohesion determines the most important quality of the binder the ability to resist external influences without disturbing the continuity of the medium at the junction of dissimilar materials, and is a parameter that determines the durability of building structures and road surfaces. In this connection, when analyzing the obtained data, this indicator was given increased attention.

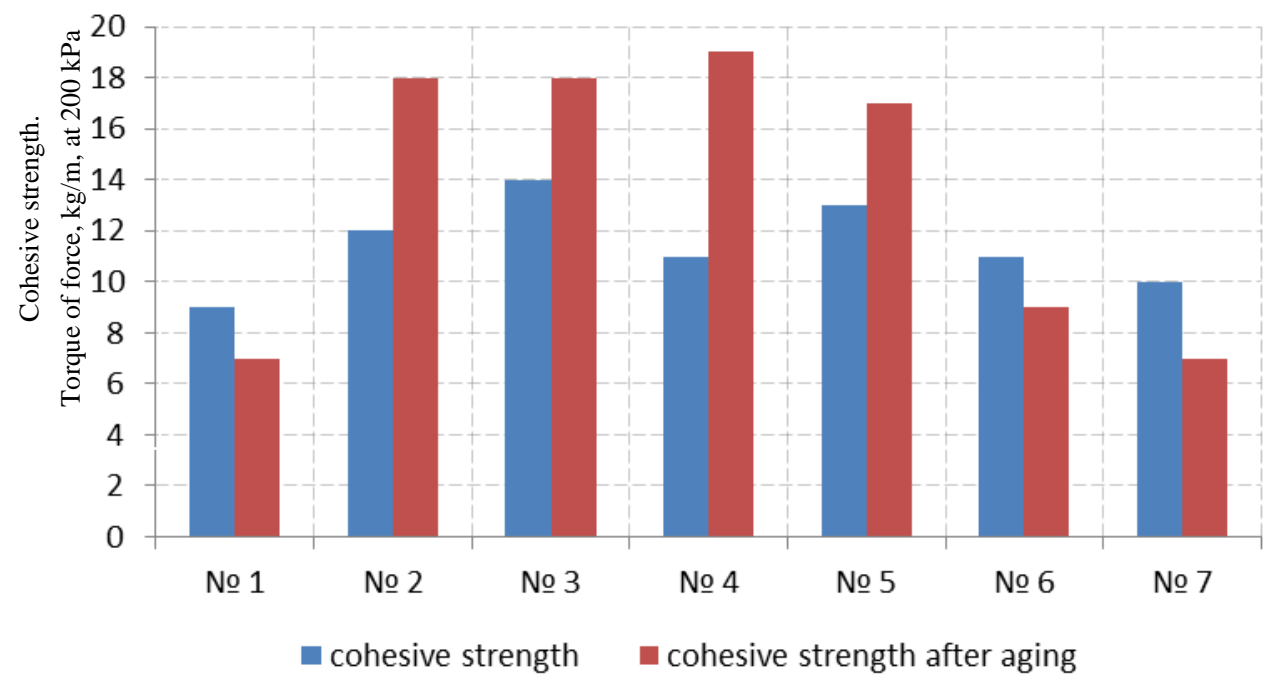

Fig. 9. Cohesive strength of PMB before and after aging according to the TFOT method

Of the series of samples under consideration, only PMB No. 2, 3 and 5 met the set of requirements for $\mathrm{PMB}$ - 60 in all respects. Which is quite logical and confirms our 
assumption that the morphological characteristics of modified binders affect the properties of the product.

Table 2 shows the heterogeneity of the PMB composition was significantly manifested when assessing the dynamic viscosity at 135 and $165^{\circ} \mathrm{C}$ after aging according to the TFOT method. For samples of series No. 1 and No. 7, the obtained viscosity indices after aging were characterized by a significant scatter of indicators, which indicated a complete violation of the stability of the PMB structure.

After aging, samples from series No. 2, 3 and 5 showed an increase in dynamic viscosity in the range of $15-20 \%$. However, in our opinion, the increase in the indicator did not occur within critical limits.

Sample from series No. 6, apparently due to intense destructive processes, showed a decrease in dynamic viscosity after aging by an average of $15 \%$, which was fully confirmed by the data in Fig. 3.

A generalized analysis of the performed studies allowed us to conclude that all the compositions of PMB samples characterized by a description of homogeneous morphological features of the structure subsequently differed in intense destructive processes.

The resulting photographs, Fig. 1, compared with the data in tables 1 and 2, sufficiently answer the question: "Why is the binder not quite high-quality?". It is impossible to obtain PMB with high consumer properties, stability to delamination and not subject to degradation processes in general, when such "polymer spiders" live in its structure, and the polymer mesh is not visible at all.

Thus, at this stage of the study, we can conclude that the "bitumen-polymer" symbiosis is mutualism.

Obviously, the main contribution to the destructive processes of PMB was made by the technological design of the process of preparing modified binders.

\subsection{The influence of the technological design of PMB preparation on its quality indicators}

At the next stage of the study, an analysis of the influence of the equipment used to prepare the PMB-60 on its consumer properties was made.

A series of binder samples prepared on equipment using a colloid mill (I), an extruder (II), and a paddle mixer (III) were studied. The results are presented in table 4.

As you can see, having the same initial components, PMB of completely different quality were obtained at the output. Conventionally, obtained binders can be positioned as follows in terms of increasing stiffness (penetration value at $25^{\circ} \mathrm{C}$ ): PMB prepared in a paddle mixer, using a colloid mill, and in an extruder.

Surprisingly, the binder prepared using an extruder lost its elastic abilities, became tough, with a high rate of cohesive strength. The increased elasticity and brittle temperature were obtained when testing a sample from series III made by means of a paddle mixer. An intermediate position was held by a series of samples II.

Based on the obtained data, it can be concluded that the binder prepared in the extruder does not meet the requirements of the regulatory documentation for PMB. It is deprived of its direct purpose - the ability to relax stresses, which can be judged by elasticity.

Obviously, this phenomenon is associated with the features of grinding and the impact of mechanical equipment on the polymer in bitumen during the preparation of PMB.

The used polymers are thermoplastic elastomers (block copolymers of butadiene and styrene type SBS) (...-CH=CH-CH=CH-CH2-CH(C6H5)-...) n. They are granular or powdery amorphous polymers of linear structure, the molecules of which contain monomeric units or blocks of butadiene and styrene, statistically arranged in a chain. In the 
process of preparing PMB, bitumen acts as a complex and multicomponent solvent for the polymer. However, the process of dissolution of high molecular weight compounds to which SBS belongs proceeds through a swelling stage. The process of preliminary swelling [16] is characteristic only for substances with a sufficiently large molecular weight, with a significant difference in the diffusion rates of the mixed substances. Swelling differs from conventional mixing in that this process is one-sided. The molecules of the maltene part of bitumen (solvent) penetrate into the free space between the links of the curved chains of SBS macromolecules, pushing apart individual sections, and then the macromolecules. During absorption by the polymer of the solvent, the unfolding of long chains of macromolecules in the liquid phase begins. After the chains of macromolecules are sufficiently distant from each other and the interaction between them is weakened, diffusion of the macromolecules in the solvent phase begins. Obviously, if the mixing process is carried out in devices with a high shear rate, the process is accompanied by polymer degradation, the breaking of long chains of macromolecules, which leads to a loss of elastic properties, and a homogenized polymer is included in the structure of the binder not as a carrier of elastic properties, but as a filler that increases its viscosity and rigidity.

Table 4. The impact of technological equipment on the properties of the resulting PMB-60

\begin{tabular}{|c|c|c|c|c|c|}
\hline \multirow{2}{*}{\multicolumn{2}{|c|}{ Name of indicator }} & \multirow{2}{*}{$\begin{array}{c}\text { Requirements } \\
\text { for PMB }-60 \\
\text { GOST, EN }\end{array}$} & \multicolumn{3}{|c|}{ No. of series of PMB -60 samples } \\
\hline & & & $\mathrm{I}$ & II & III \\
\hline \multicolumn{2}{|c|}{$\begin{array}{l}\text { Needle penetration depth }(0.1 \mathrm{~mm}) \text {, } \\
\text { at } 25^{\circ} \mathrm{C} \\
\text { at } 0^{0} \mathrm{C}\end{array}$} & $\begin{array}{l}60 \\
32 \\
\end{array}$ & $\begin{array}{l}64 \\
32 \\
\end{array}$ & $\begin{array}{l}61 \\
30\end{array}$ & $\begin{array}{l}68 \\
34\end{array}$ \\
\hline \multicolumn{2}{|c|}{ Softening temperature, ${ }^{\circ} \mathrm{C}$} & 54 & 68 & 70 & 65 \\
\hline \multicolumn{2}{|l|}{ Homogeneity } & homogeneous & hom. & hom. & hom. \\
\hline \multicolumn{2}{|c|}{ Brittle temperature, ${ }^{0} \mathrm{C}$} & -20 & -22 & -21 & -24 \\
\hline \multicolumn{2}{|c|}{$\begin{array}{l}\text { Extensibility, } \mathrm{cm}^{\Delta} \mathrm{L} \text {, } \\
\text { at } 25^{\circ} \mathrm{C} \\
\text { at } 0^{\circ} \mathrm{C} \\
\end{array}$} & $\begin{array}{l}25 \\
11 \\
\end{array}$ & $\begin{array}{l}76 \\
28\end{array}$ & $\begin{array}{l}52 \\
15\end{array}$ & $\begin{array}{l}88 \\
32\end{array}$ \\
\hline \multicolumn{2}{|c|}{$\begin{array}{l}\text { Elasticity, } \%{ }^{\Delta} \mathrm{L} \\
\quad \text { at } 25^{\circ} \mathrm{C} \\
\text { at } 0^{0} \mathrm{C}\end{array}$} & $\begin{array}{l}80 \\
70\end{array}$ & $\begin{array}{l}95 \\
74\end{array}$ & $\begin{array}{l}71 \\
58\end{array}$ & $\begin{array}{l}98 \\
88\end{array}$ \\
\hline \multicolumn{2}{|c|}{$\begin{array}{l}\text { Cohesive strength. Torque of force, } \\
\mathrm{kgf} / \mathrm{m} \text {, at } 200 \mathrm{kPa}\end{array}$} & - & 12 & 14 & 13 \\
\hline \multicolumn{2}{|c|}{$\begin{array}{l}\text { Resistance to delamination: } \\
\text { - difference in brittle temperature, }{ }^{0} \mathrm{C} \\
\text { - difference in softening temperature, } \\
{ }^{0} \mathrm{C}\end{array}$} & $\overline{5}$ & $\begin{array}{l}2 \\
2\end{array}$ & $\begin{array}{l}2 \\
1\end{array}$ & $\begin{array}{l}3 \\
6\end{array}$ \\
\hline \multicolumn{2}{|c|}{$\begin{array}{l}\text { Change in softening temperature after } \\
\text { warming up, }{ }^{0} \mathrm{C}\end{array}$} & 5 & 2 & 3 & 4 \\
\hline \multirow{2}{*}{$\begin{array}{l}\text { Resistance to } \\
\text { aging. TFOT } \\
\text { method }\end{array}$} & change in weight, $\%$ & 0.4 & 0.3 & 0.3 & 0.5 \\
\hline & $\begin{array}{l}\text { change in softening } \\
\text { temperature, }{ }^{0} \mathrm{C}\end{array}$ & 4 & 2 & 3 & 3 \\
\hline
\end{tabular}

If we consider a technology based on the use of a paddle mixer, then it is necessary to mention that at high temperatures, the polymer-bitumen binder is in the form of a single phase [14]. However, even at room temperature, all PMBs, in view of the significant difference in the components of the modified binder in molecular parameters, consist of more than one phase, each of which differs from the properties of the original bitumen. The distribution, extent, and homogeneity of various phases of PMB largely depend on the technology of polymer introduction $[17,18]$. When using devices with a low shear rate (mixers), the particle size of the macromolecules is slightly increased, which gives the 
binder increased elasticity and manufacturability, but from the point of view of the laws of colloidal chemistry, makes it unstable during storage.

\section{Conclusions}

In the first part of the study, a direct relationship was established between the influence of the morphology of PMB on the aggregate of consumer properties of binders, and first of all, such as destruction from delamination and aging. Observation of a significant number of individual particles of uncertain shapes and sizes in a modified binder is proportional to the intensity of destructive processes in the structure of the binder. Obviously, the hardware implementation of the PMB preparation process makes a significant contribution to the morphological parameters forming in the binder with possible subsequent destruction.

The validity of this assumption was confirmed in the second part of the study. It was experimentally proven that the achievement of high elastic properties of PMB is possible using paddle mixers that do not damage the long polymer macromolecules during the process. However, such binders are prone to delamination. To eliminate this negative aspect, the use of additional crosslinking agents is necessary.

It is established that the extruder can be attributed to equipment, the use of which is rather controversial for the production of PMB. A binder of the appropriate quality was obtained using a colloidal mill. Thus, the choice of raw materials for PMB and the technological equipment for its production must be approached comprehensively.

\section{References}

1. Yu.A. Kutin, E.G. Telyashev, G.N. Viktorova, Khares Shaalyan Mushref. Road World 67. 59-63. (2013)

2. V.A. Zolotarev Road bitumen binders: a textbook for university students. Moscow, Publishing House DIA, (2014)

3. L.M. Gokhman Association of researchers of asphalt concrete. Moscow Automobile and Road State Technical University (MADI). Pp. 39-46. (2019)

4. O.N. Kindeev, M.A. Vysotskaya, S.Yu. Shekhovtsova Vestnik BGTU im. V.G. Shukhov. 1. 26-31. (2016)

5. H. Soenen, X.Lu, P. Redelius SBS Modified Bitumen's: Does their morphology and storage stability influence asphalt mix performance? https://www.nynas.com/en/product-areas/bitumen-for-paving/bitumen-for-pavingapplications/knowledge-tank/hej

6. D.A. Ayupov, Yu.N. Khakimullin, D.B. Makarov Bulletin of the Technological University. 19. (2016)

7. V.I. Polyakova S.V. Polyakova Roads and bridges. 277-298. (2013)

8. A. Roman, P. Olga et al., International Journal of Applied Engineering Research. 12 (22). 11926-11932 (2017)

9. D. Lesueur Advances in Colloid and Interface Science. 145 (1-2). 42-82. (2009)

10. L.M. Gokhman Complex organic binders based on block copolymers of the SBS type: textbook. allowance Moscow, Ekoninform (2004)

11. A.A. Gureev Highways. 1. 48-50. (2012)

12. V.A. Zolotarev Bitumens modified with polymers and additives. Selected Works. 2. (2013) 
13. L. Zani, F. Giustozzi, J. Harvey Construction and Building Materials. 145. 326-335. (2017)

14. J. Zhu, R. Balieu, X. Lu, N. Kringos Journal of Materials Science. 52 (11). 6525-6541. (2017)

15. G. Holleran, I. Holleran, D.J. Wilson Conference Series: Materials Science and Engineering. Building up Efficient and Sustainable Transport Infrastructure. 236 (1) No. 012009. (2017)

16. H. Zainab, I. Kamaruddin et al., Road Materials and Pavement Design. 18. 249-258. (2017)

17. C. Oliviero Rossi, S. Ashimova et al., Applied Sciences (Switzerland). 7(8) (2017)

18. H. Zainab, I. Kamaruddin et al., International Conference on Advances in Sustainable Construction Materials and Civil Engineering Systems (2017) 